\title{
Post-graduate studies in South Africa: Myths, misconcep- tions and challenges
}

\author{
J. Mouton \\ Centre for Research on Science and Technology \\ University of Stellenbosch \\ e-mail: jm6@sun.ac.za
}

\begin{abstract}
The article interrogates some of the current views and myths around the so-called 'inefficiency' of the management of postgraduate studies in South Africa. In this regard data a re presented on recent trends in postgraduate completion rates at the doctoral level; as well as on comparative data on throughput rates. I argue that the current discourse in South A frican higher education is obsessed with concerns of efficiency rather than effectiveness and quality. In this process, we focus to o much on managerial and administrative solutions rather than on the challenges posed by academically underprepared postgraduate students.
\end{abstract}

\section{INTRODUCTION}

For various reasons, the state of post-graduate studies in South Africa has come under increasing scrutiny in recent years. Questions about the quality of post-graduate supervision, possible shifts in the nature and focus of theses and dissertations and the implications thereof for supervisory models, the slow growth in masters and especially doctoral graduates and so on are much more prevalent nowadays than even five years ago.

There are at least three reasons why we are witnessing increased interest in the state of post-graduate studies.

First, the institutional audits of the HEQC over the past three to four years have demanded that universities look more closely at various aspects of the quality of post-graduate studies. The quality of management systems and procedures, supervision and examination processes and support to post-graduate students have all come under (renewed) scrutiny. Perhaps surprisingly, informal feedback has revealed that most universities, including the more established research universities, are not doing enough to ensure that the necessary conditions are in place to ensure quality of PGstudies across the board.

Second, research undertaken by the Centre for Research on Science and Technology 
at Stellenbosch University on the ageing of active scientists in public science in South Africa, have led to further concerns about the provision of quality supervision to the next generation of scholars and scientists. The most productive scientists often also assume disproportionate supervisory loads. The fact that nearly half of our total research output in the country is now produced by scientists over the age of 50 remains a major matter of concern. Unless we take immediate and incisive steps to reverse this trend, we will not only see an increasing decline in overall research production in the country, but also the steady erosion of the supervisory capacity in the system.

Third, the increasing internationalisation and even institutionalisation of corporatism and managerialism in South African universities, has brought with it a concomitant shift in attention from concerns of quality and effectiveness to concerns about efficiency and throughput. In the field of post-graduate studies, this trend has manifested itself in a growing belief in certain circles that the management and supervision of Masters and Doctoral students at South African universities is inefficient. It is inefficient, because it is believed that these students take too long (on average) to complete their studies and that the conversion rate from Masters to Doctoral is too small.

It is this belief in the inefficiency of post-graduate management and supervision that is the focus of this article. In fact, I will argue that this belief has become so widelyheld and generally accepted by various constituencies and interest groups in higher education in the country that is assuming a myth-like status.

\section{ON MYTHS}

I understand 'myths' to be widely held beliefs that essentially distort or misrepresent reality. In addition they are used (or 'misused') to maintain or promote certain courses of action or relations of power. Myths are more than mere fanciful stories - they are legitimizing discourses (e.g. the myths of racial or male superiority). Such distorted beliefs (as in the myth of the Afrikaner volk as a chosen nation or of the superiority of Aryan people) constitute the core of powerful ideologies (Afrikaner-nationalism or National socialism).

Myths, in this sense, need to be taken seriously. They are not innocent but have farreaching consequences. Myths get internalised in the decisions, actions and practices of peoples and institutions. Because they are assumed to have normative or at least prescriptive status, they are often employed to sanction what counts as acceptable or good. In these ways, they find their way into institutional discourses, policies and systems and begin to steer practices in certain specific directions. For all these reasons, it is important to understand that it is not nearly enough merely to 'tolerate' myths. They need to be exposed as such and debunked.

In contrast to 'myths', 'misconceptions'- such that the earth is flat - are simply false beliefs or opinions that can be (and often are) corrected once sufficient and credible evidence is brought to bear upon them. Misconceptions are essentially false beliefs - descriptive or explanatory claims that are accepted at one point in time to be true 
because the best available evidence warranted their acceptance. Further evidence based on more accurate measurements, new empirical discoveries and often more sophisticated scientific techniques show that our acceptance of these beliefs was premature and that they are essentially false.

But sometimes misconceptions get appropriated into mythical discourses. Myths (e.g. eugenics) typically incorporate selected falsehoods (misconceptions) in order to create and portray a semblance of evidentiary support. Therefore, a first step in debunking myths is to start by exposing the misconceptions that form part and parcel of them and which mistakenly give them a pseudo (scientific) credibility.

\section{THE INEFFICIENCY MYTH}

I would argue that a set of beliefs around post-graduate, and in particular, doctoral studies in South Africa, has emerged over the past number of years and at the same time assumed near mythical status. These beliefs have become widespread and powerful, but - I will argue - are composed of very obvious misconceptions. The myth can be articulated in the following terms:

Doctoral students in SA take too long to complete their studies. In addition, too many students drop out early in their doctoral students. These failures are mainly due to inefficient supervision. SA supervisors, and by implication, the system of doctoral supervision in the country, is not producing enough doctoral graduates within a reasonable (3-4 years) time period. The challenge is to develop policies and practices that will monitor supervisory practices and ensure that these inefficiencies are addressed. By implication, if we were to improve the efficiency of our supervisors, we should see an immediate increase in doctoral throughputs and completion rates.

So what is the source of the seemingly widely view - even myth - that South African universities are inefficient in its production of doctoral graduates?

In March 2005 the Department of Education published a report in which it was shown quite clearly that throughput rates in undergraduate courses at most SA universities are extremely low. As the data shows, only about $40 \%$ of all students who enter higher education manage to complete their first degree:

... higher education is producing fewer graduates than it should, and one of the main causes of this under-production is high levels of student drop-outs. A detailed study of the 120000 undergraduates who entered the higher education system for the first time in the 2000 academic year confirms these conclusions. The data show that about 36000 (or 30\%) of the total cohort of 120000 first-time entering undergraduates in universities and technikons dropped out at the end of their first year of studies, and that a further 24000 dropped out after either two or three years of study. The total of the cohort that had dropped out by the 2003 academic year was therefore 60000 (or $50 \%$ ). Only 26500 (or $22 \%$ ) of the total cohort had graduated by the end of their third or fourth years of study. The remaining 33500 were studying in 2003 but did 
not complete their qualifications in that year. It is seems possible that this first-time entering cohort of the 2000 academic year may not achieve an overall graduation rate of even $40 \%$ (DoE 2005, 9).

Although not claimed explicitly in this report, one interpretation of these trends that found its way into public discourse around the matter was that the universities are not doing enough to limit the 'wastage' of undergraduate students. One could argue that universities, even if only implicitly, were being 'accused' of not being sufficiently effective and efficient in the management of their undergraduate student throughput rates. It was against this background, that the NRF in 2005 first propagated the idea of 'The $\mathrm{PhD}$ as driver'. The core ideas are well captured in the following section from the NRF Businessplan in 2007:

Responding to challenges facing the South African National System of Innovation (NSI) the NRF identified a key driver for all its programmes, "the production of large numbers of high quality PhDs that are required to provide the bedrock for an innovative and entrepreneurial knowledge society". Inherent in the understanding of $\mathrm{PhD}$ as a driver, is that the entire education system must be effective, from pre-school to primary, through senior phase and eventually at tertiary level. Efforts to de-link the different parts of the chain will render the implementation of any strategies less effective and unsustainable in the longer term. While proposed interventions are concentrated at postgraduate level, the NRF will continue to advocate at policy level for an effective education system and will also work alongside other stakeholders in advocating for an effective and efficient education system in its entirety (NRF 2007, 8).

The reference to greater efficiency in the NRF document derives from an earlier statement in the same document where it is pointed out that SA higher education institutions only produce on average 1000 doctoral graduates from a pool of $500000+$ enrolled students. It therefore 'takes 500 students to produce 1 doctorate'!

This sentiment was restated even more clearly in the Institutional Development Research Programme of the NRF for 2007 where one of the challenges facing the system is the 'efficiency of the current HE system'. The authors continue:

The number of students ultimately exiting the HE system is comparatively small. In 2004, of the 528 undergraduates enrolled at universities, only 1 student exits the HE sector with a doctoral degree. This demonstrates a high degree of inefficiency (NRF 2007, Section 3)

What evidence is there to support these claims? What studies have been produced to show that the production of doctoral students in South Africa is inefficient? And compared to whom? We are not aware of any such studies, but if there were any, they would have to demonstrate two things: 
- That doctoral students in SA take longer to complete their degrees than international averages (TTD) and/or that we have higher drop-out rates amongst our doctoral enrolments.

- Even if this is shown, one would have to show that longer than average completion rates and above average attrition rates can be attributed to poor (supervisory) management of doctoral students or weak institutional support rather than other factors.

\section{THE MISCONCEPTIONS}

But let us start by revisiting the NRF calculations. I contend that the NRF figures are in fact misleading.

First, the number of 1000 refers to doctoral graduates whereas the number of 500000 to all undergraduate and post-graduate students enrolled in 2003. If one wishes to compare enrolments at one level with enrolments at another level, the ratio would change considerably. In 2004 there were approximately 9000 doctoral enrolments compared to 500000 overall enrolment. A less misleading ratio would be to compare the number of doctoral graduates to the number of bachelor graduates. This ratio for the past 15 years averages at 40 to 1 . (So it takes 40 bachelor graduates to produce one $\mathrm{PhD}$.).

Second, the HEMIS figures of the Department of Education further distinguish between General and Professional Bachelor graduates. Since very few doctoral graduates emerge from the ranks of professional disciplines and fields such as social work, nursing, clinical fields and even law, a fairer calculation would exclude the category of 'professional' bachelors. The ratio of doctoral graduates to general bachelor graduates on average for the period 1990-2004 is 28 to 1 . But it is also worth noting that this ratio has been improving significantly over the past five years to stand at 22 to 1 in 2004. (So, it really takes 22 graduates to produce one $\mathrm{PhD}$ )

Finally, it is perhaps even more appropriate to ask how many Masters students it takes to produce one doctoral student since this is the real immediate source or pool for doctoral enrolments. The average for the past 15 years is just over 6 to 1, although this ratio is worse than it was in the late nineties. However, we need to remind ourselves that a very large proportion of Masters graduates (approximately one third) are MBA graduates. Again, since very few MBA's convert into doctoral studies, it is in fact ultimately more reasonable to argue that we convert approximately every third or fourth Masters graduate into a Doctoral graduate. And this suddenly does not seem to be an unacceptable low rate of conversion!

Having addressed some of the sources of the 'inefficiency myth' and its underlying misconceptions, I now shift my focus to the most recent available evidence on these matters and what they imply for our 'assessment' of the inefficiency myth. I present evidence in two areas:

- A profile of current doctoral enrolments and graduations in SA

- Data on current throughput rates and compare these with international data. 


\section{THE NATIONAL PRODUCTION OF DOCTORATES}

Figure 1 presents the trends in doctoral enrolments and graduations for the period 2000 to 2005. The data, provided by the Department of Education HEMIS system, show clearly that the growth in enrolments (nearly $50 \%$ over this whole period) is much higher that an overall growth in graduation rates (less than $20 \%$ ). ${ }^{1}$

Figure 1: Doctoral enrolments and graduations in SA (2000-2005)

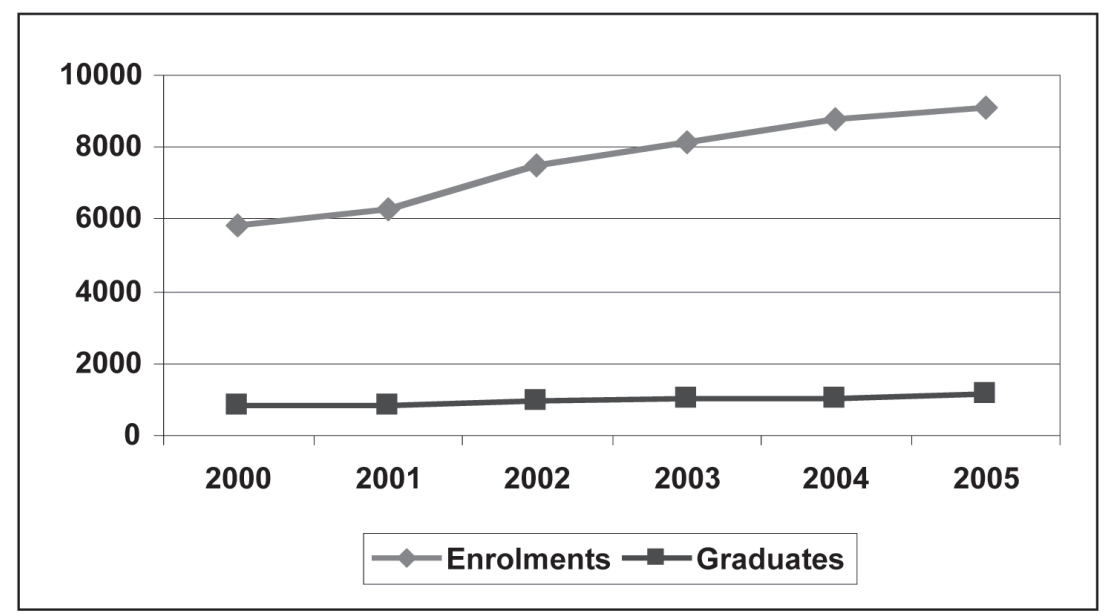

From a transformation perspective it is also worth showing that the biggest growth in graduation rates has been amongst female graduates (Figure 2) and black graduates (Figure 3). If current trends continue, we should within 2 to 3 years have achieved a $50 / 50$ split as far as gender and race (black/white) numbers are concerned.

Figure 2: Gender breakdown of doctoral graduations in SA (2000-2005)

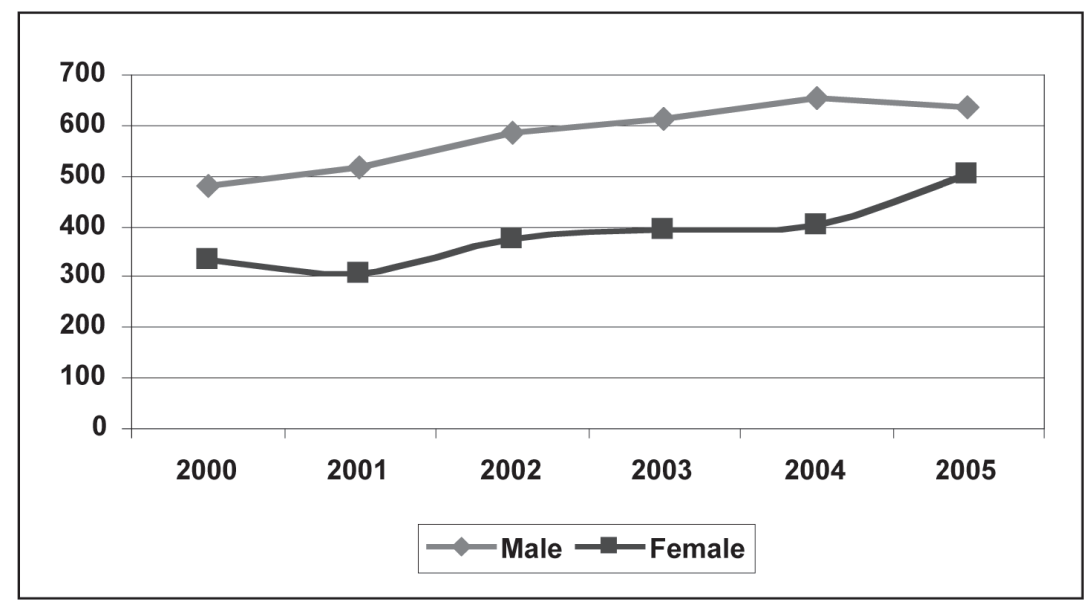


Figure 3: Racial breakdown of doctoral graduations in SA (2000-2005)

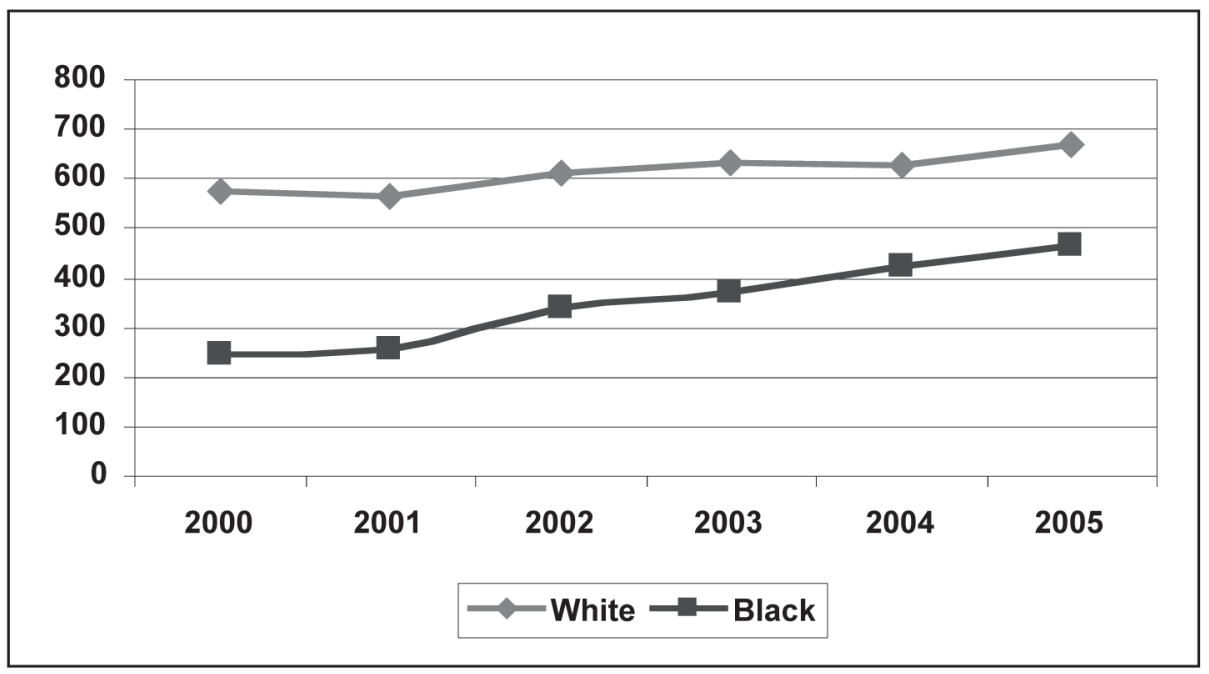

The breakdown by scientific field for doctoral graduates (Figure 4) reveals that growth has been most pronounced for the natural and social sciences. At the same time, the arts and humanities have seen a substantial decline in numbers of doctoral graduates, whereas the picture for graduates in the health and engineering sciences have remained very much the same.

Figure 4: Breakdown of doctoral graduations in SA by main scientific field (2000-2005)

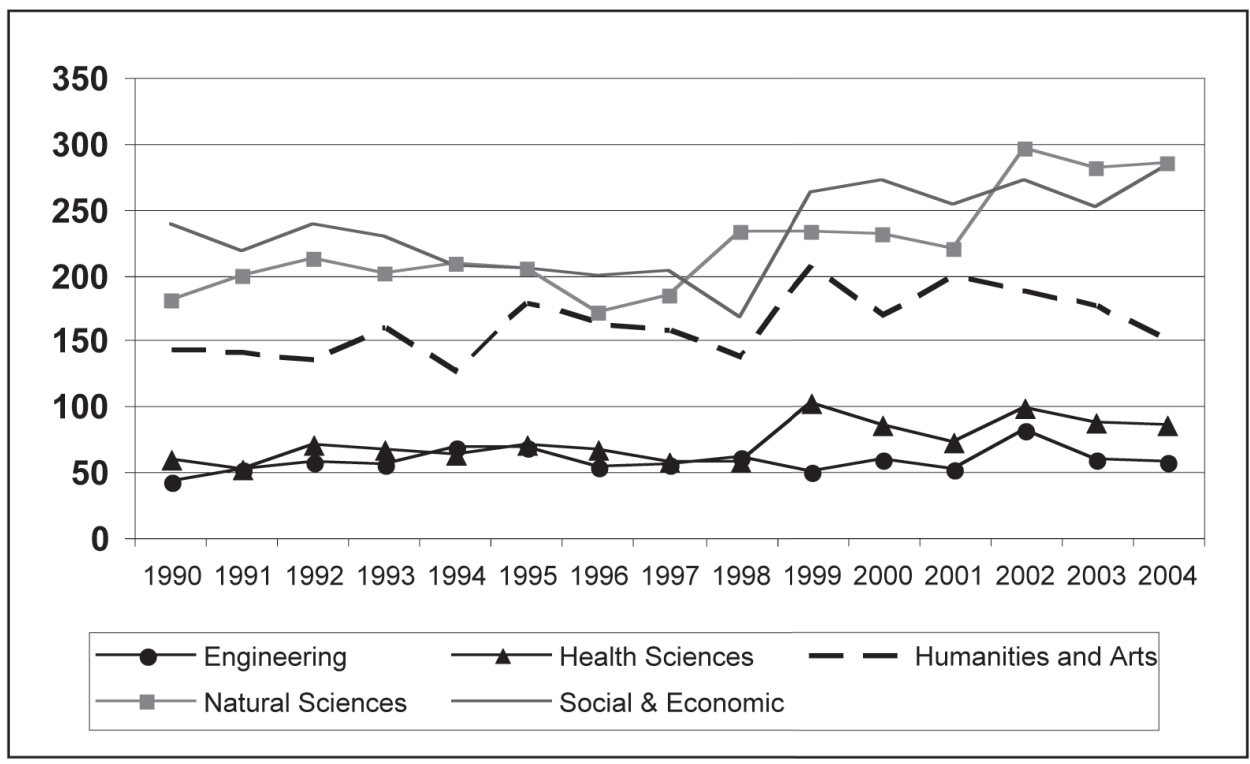


A breakdown by institution (Table 1) shows the dominance of a few institutions in the production doctoral graduates over the past 15 years. Nearly three quarters of all doctoral graduates are confined to 6 universities.

Table 1: Doctoral graduates by University: Three year windows 1990-2004

\begin{tabular}{|l|l|l|l|l|l|l|l|}
\hline Institution & $\begin{array}{l}\mathbf{1 9 9 0 -} \\
\mathbf{1 9 9 2}\end{array}$ & $\begin{array}{l}\mathbf{1 9 9 3 -} \\
\mathbf{1 9 9 5}\end{array}$ & $\begin{array}{l}\mathbf{1 9 9 6 -} \\
\mathbf{1 9 9 8}\end{array}$ & $\begin{array}{l}\mathbf{1 9 9 9 -} \\
\mathbf{2 0 0 1}\end{array}$ & $\begin{array}{l}\mathbf{2 0 0 2 -} \\
\mathbf{2 0 0 4}\end{array}$ & Total & Col \% \\
\hline University of Pretoria & 322 & 357 & 286 & 378 & 482 & 1825 & 16.22 \\
\hline $\begin{array}{l}\text { University of South } \\
\text { Africa }\end{array}$ & 294 & 267 & 235 & 308 & 181 & 1285 & 11.42 \\
\hline University of Cape Town & 212 & 232 & 232 & 277 & 291 & 1244 & 11.06 \\
\hline Stellenbosch University & 223 & 213 & 207 & 258 & 282 & 1183 & 10.52 \\
\hline $\begin{array}{l}\text { University of the } \\
\text { Witwatersrand }\end{array}$ & 228 & 231 & 199 & 206 & 243 & 1107 & 9.84 \\
\hline $\begin{array}{l}\text { University of Kwazulu } \\
\text { Natal }\end{array}$ & 185 & 203 & 194 & 179 & 225 & 986 & 8.76 \\
\hline $\begin{array}{l}\text { University of the Free } \\
\text { State }\end{array}$ & 159 & 149 & 132 & 171 & 206 & 817 & 7.26 \\
\hline $\begin{array}{l}\text { University of } \\
\text { Johannesburg }\end{array}$ & 138 & 148 & 163 & 211 & 118 & 778 & 6.92 \\
\hline North West University & 88 & 122 & 102 & 170 & 221 & 703 & 6.25 \\
\hline Rhodes University & 57 & 65 & 71 & 81 & 124 & 398 & 3.54 \\
\hline Total output & 2042 & 2115 & 1970 & 2468 & 2655 & 11250 & 1.00 \\
\hline
\end{tabular}

\section{NATIONAL THROUGHPUT RATES AND INTERNATIONAL COMPARISONS}

Finally, we focus on throughput rates. Our analysis was conducted by taking all doctoral students who have graduated since 2000 (Hemis data). The HEMIS dataset indicates the first year of registration of all students which enables one to calculate number of years to completion of study for the past 6 years (until 2005). ${ }^{2}$ For this period we could identify valid data for 4480 students in total. Figure 5 presents the trend data for this period. 
Figure 5: Completion rates for doctoral students (2000-2005)

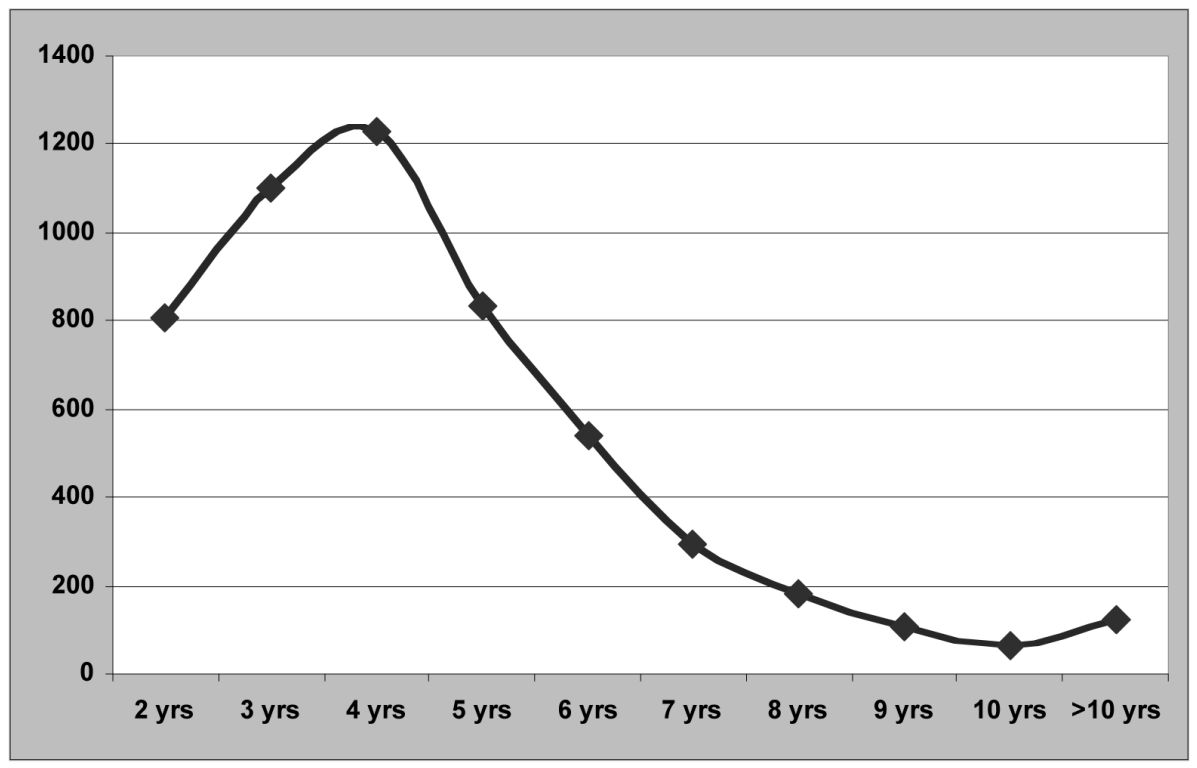

The average time to completion for this group is approximately 4.7 years. Figure 5 shows clearly that the vast majority $68 \%$ of students complete their studies within the first 5 years (in fact $77 \%$ ). Mindful of the fact that completion rates might vary significantly across scientific fields, we also did a breakdown by main scientific field (Figure 6). The results, perhaps surprisingly, did not reveal huge differences.

Figure 6: Doctoral graduates by scientific field (2000-2005)

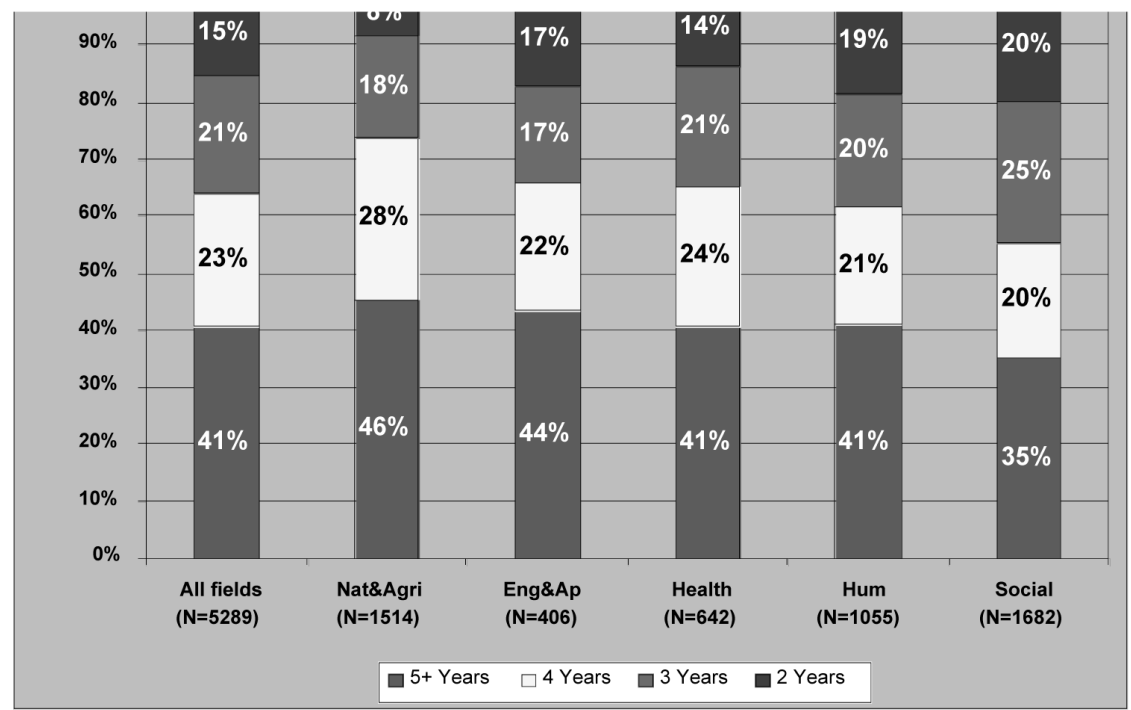


How do these trends compare with international results? In one of the most comprehensive studies recently undertaken in the USA, the US Council of Graduate Schools (Denecke 2005) investigated the cumulative doctoral completion rates for Students. A summary graph (Figure 7) shows that between $50 \%$ and $60 \%$ of all students complete their studies within 10 years. It also shows that the majority of students take between 5 and 7 years to complete their doctoral programmes. One should, of course, keep in mind that the structure of most doctoral programmes in the USA is quite different from the South African model. Most doctoral programmes follow after 4 or 5 years of undergraduate studies with no intermediate Honnours or Masters programme.

Figure 7: Cumulative 10-year doctoral completion rates from original cohorts by broad field

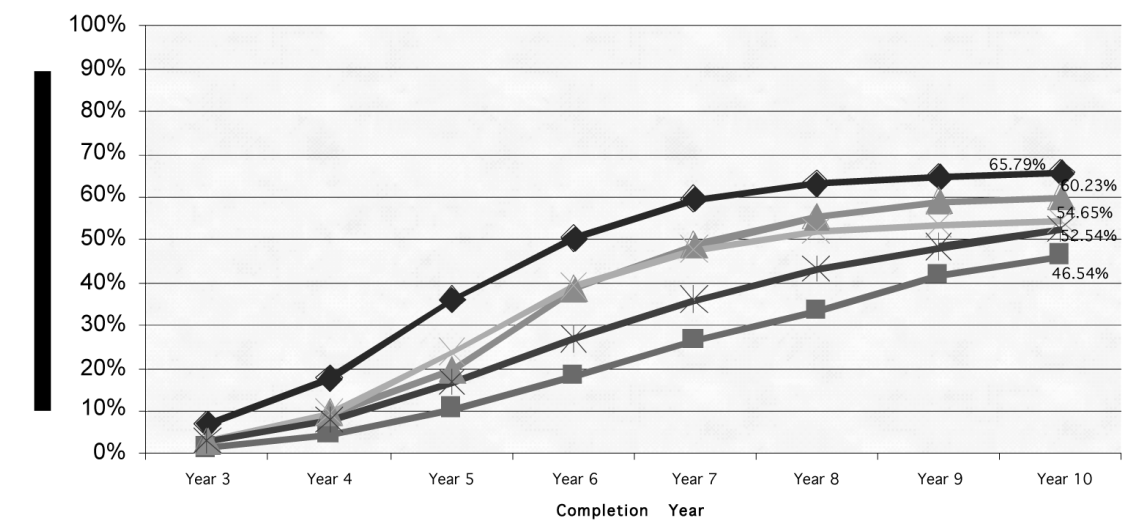

In another recent study by Fred Hall, he compares the results of doctoral students at three prominent universities in Australia (Melbourne), Canada (MacMaster) and USA (Duke). Table 2 below presents these comparative results both for completion rates as well as medium time to degree completion (TTD).

Table 2: Comparative doctoral statistics for three universities

\begin{tabular}{|l|l|l|l|l|l|l|}
\hline & \multicolumn{2}{l}{ Melbourne } & \multicolumn{2}{l|}{ MacMaster } & \multicolumn{2}{l|}{ Duke } \\
\cline { 2 - 8 } & \% com & Med TTD & \% com & Med TTD & \% com & Med TTD \\
\hline Arts & 54 & 5.7 & 53 & 5.0 & 61 & 6.3 \\
\hline Engineering & 69 & 5.0 & 76 & 4.3 & 60 & 4.9 \\
\hline Life Sciences & 76 & 4.7 & 77 & 4.0 & 73 & 5.5 \\
\hline Physical Sciences & 74 & 4.7 & 75 & 4.0 & 60 & 5.0 \\
\hline
\end{tabular}


This comparison with two recent studies already suggests that the time to completion of degree of South African doctoral students compares very favourably with international trends. This is a limited comparison not only in terms of the number of studies compared, but also because one has to take into consideration the qualitative differences in the doctoral systems in different countries. However, I would contend that even if one takes such possible differences into account, our analysis of the South African data shows very clearly that time to degree is very competitive. The fact that the average doctoral student in South Africa over the past six years has taken approximately 4.7 years to complete his or her degree and that the majority complete within 5 years certainly do not point to unacceptable completion rates.

A caveat, though, is in order. We have no systematic and credible data on doctoral attrition rates for South Africa. Anecdotal experiences would suggest that between 30 and 40 per cent of all students who enroll, never complete their studies. If these experiences are accurate, it would still suggest that our attrition rates are in line with international experiences. This means, however, that we cannot comment on the throughput rates of doctoral students in our system. The completion rates reported above obviously only refer to those students who remained in the system.

\section{CONCLUDING OBSERVATIONS}

We agree with the NRF and other commentators that the production of doctoral graduates in South Africa is growing too slowly. At current rates, South Africa will take between six and seven years to increase its current output to about 1500 doctorates per year. We do not believe that this relatively low production is due to inherent inefficiencies in the higher education system. The data presented in this article show very clearly that our doctoral completion rates are congruent with international trends. We would also contend that our attrition rates (even if they are as high as $40 \%$ ) would still be in line with international experiences.

The real problem and challenge in South Africa is that we have too few doctoral students in the system. In fact the overall participation rates in HE for the country compared to international trends are very low. The most recent data that we could access refer to doctoral participation rates in EU-countries. 'Doctoral participation' is measured by the number of $\mathrm{PhD}$ graduates in Science and Engineering fields per thousand of the population for the age group 25-34. Based on this criterion Sweden tops the EU-list (Figure 8) with 1.24 doctoral graduates per 1000 of the age group (24-34) in 2000. The EU-average for this tear was 0.42 whereas the statistic for South Africa was a mere 0.05 . This means that in 2000 we produced one eighth of the EU-average for doctoral graduates in Science and Engineering.

Again, one should be careful to place too much weight on this single comparison as it is rather dated results (and our doctoral participation rates increased more recently) and also not inclusive of all scientific fields. Nevertheless, it remains a good indication that we do not produce enough doctoral graduates for our society and economy. 
Figure 8: International comparison of doctoral participation rates (2000)



(Source: EC Report on Science)

\section{IN CONCLUSION}

We believe that the problem with doctoral production in South Africa is NOT primarily with completion and attrition rates. The evidence cited here gives no support to the view that SA is doing worse than the rest of the world. There is in fact NO evidence to support any interpretation that points to a presumed inefficiency in the system of doctoral supervision. In fact - if we keep some basic facts in mind - a contrary view emerges. Over the past ten years, academic staff numbers in SA have increased by less than $20 \%$ but over the same period

- Masters and doctoral enrolments and graduations have increased more than threefold

- Research output by academic staff in this period has increased from 5000 to 6600 output units

- Research contract income generated by academic staff at the top research universities has more than doubled and even tripled in some cases.

The fact that all of these achievements have materialized amidst major institutional changes and audits, curricular reforms and even mergers are more suggestive of an extremely efficient higher education system!

If one accepts these conclusions it does not, however, follow that there are not serious shortcomings in current systems and practices of doctoral supervision and support in our 
HE system. In fact, the problem with myths is that they often deflect our attention from the real problems. Once we get rid of the 'fixation' with issues of throughput and (in) efficiency and start to face the real challenges, we will recognize the seriousness of other problems - most of which speak to the matter of the quality of our doctoral students and studies. There are indeed serious systemic issues that require our attention such as:

- Too many overburdened and inexperienced supervisors

- Insufficient research preparation for doctoral students

- Insufficient national and institutional financial support for students

- Insufficient institutional attention and resources devoted to post-graduate support.

I therefore conclude with four proposals that are directed at these challenges:

- We need to attract more PhD candidates to selected, well-established and effectively managed doctoral programmes through targeted financial support schemes.

- We need to encourage institutions to think creatively about making doctoral appointments within a structured career planning framework (that includes post-doctoral career options).

- We need to actively lobby the NRF (and Treasury) to increase funding for PG studies in order to provide realistic support for full-time doctoral studies.

- We should seriously consider launching a national doctoral or post-graduate academy to provide prospective doctoral candidates with a better foundation in research methodology and thesis management and also provide high-quality seminars and workshops to build the capacity of our supervisors.

\section{NOTES}

1. My sincere appreciation to Nelius Boshoff for the analysis of the HEMIS data.

2. It transpired during the analysis that there are some inaccuracies in the dataset that pertain mostly to information captured before 2000. So, for example, in some few cases the data would show that doctoral students took less than one year to complete their studies! We have ignored obvious errors like these.

\section{REFERENCES}

Department of Education. 2005. Student enrolment planning in public higher education. Pretoria.

Hall, F., B. Evans and M. Nerad. 2005. 'Are International comparisons feasible for $\mathrm{PhD}$ times-to-degree (TTD) and completion rates?' Annual Meeting of the Council of Graduate Schools, Palm Desert, California.

National Research Foundation. 2007. Institutional Development Research Programme: Programme Framework 2007-2011. Pretoria.

Denecke, D. 2005. 'Ph.D. Completion Project, overview and update.' Council of Graduate Schools, CGS Summer Workshop, Santa Fe, NM, July 13, 2005. 